\title{
Angiotensin II blockers in obstructive pulmonary disease: a randomised controlled trial
}

\author{
S. Andreas*\#, C. Herrmann-Lingen ${ }^{\Uparrow}$, T. Raupach" ${ }^{\#}$, L. Lüthje ${ }^{\#}$, J.A. Fabricius ${ }^{\#}$, \\ N. Hruska ${ }^{\#}$, W. Körber ${ }^{+}$, B. Büchner ${ }^{\dagger}$, C-P. Criée ${ }^{+}$, G. Hasenfuß ${ }^{\#}$ and P. Calverley ${ }^{\S}$
}

ABSTRACT: In chronic obstructive pulmonary disease (COPD), the sympathetic nervous system, as well as the renin-angiotensin system, is activated with possible negative systemic effects on skeletal muscles. Angiotensin II type-1 receptor blockers inhibit the sympathetic and reninangiotensin systems and might improve skeletal and respiratory muscle strength in patients in whom these systems are activated.

The effects of the angiotensin receptor blocker irbesartan given over 4 months was evaluated in 60 patients with COPD and a forced expiratory volume in one second of $<50 \%$ of the predicted value and without obvious cardiovascular disease that would necessitate the administration of an angiotensin-converting enzyme inhibitor or an angiotensin receptor blocker.

Irbesartan was well tolerated, but did not exert a significant effect on the primary end-point maximum inspiratory pressure. Spirometric results were not affected, but total lung capacity was reduced. Irbesartan led to a significant decrease in haematocrit $(46.4 \pm 3.6$ to $43.9 \pm 4.3 \%$ versus $47.5 \pm 2.4$ to $48.7 \pm 3.0 \%$ with placebo).

In conclusion, respiratory muscle strength in chronic obstructive pulmonary disease patients was not influenced by angiotensin II receptor blockade. However, the changes in haematocrit and total lung capacity following irbesartan raise the possibility that well-known cardiovascular drugs can produce unanticipated beneficial effects in chronic obstructive pulmonary disease patients.

KEYWORDS: Chronic obstructive pulmonary disease, haematocrit, irbesartan, respiratory muscle

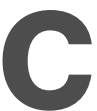
hronic obstructive pulmonary disease (COPD) is a major cause of death and disability worldwide, and the burden of this disorder will continue to increase in the coming decades [1]. Treating COPD improves lung function, although it is unlikely to slow the steady downhill course of the disease or even reduce mortality $[1,2]$. The pathophysiology of COPD is not limited to the lungs. Indeed, COPD has been identified as having a systemic or muscle component $[3,4]$.

In COPD, the sympathetic nervous system, as well as the renin-angiotensin system (RAS), is activated [5-7], with potentially negative systemic effects, on skeletal muscles for example. Angiotensin II type-1 receptor $\left(\mathrm{AT}_{1}\right)$ blockers inhibit the sympathetic and renin-angiotensin systems [8] and improve both the quality of life and longevity in patients with heart failure. The $\mathrm{AT}_{1}$ receptor blocker irbesartan prevents the development of muscle atrophy in a rat model of right heart failure [9]. Moreover, in patients with left heart failure, maximum inspiratory pressure improved after treatment with angiotensinconverting enzyme (ACE) inhibition [10].

Activation of the RAS is associated with the development of secondary erythrocytosis in hypoxaemic patients with COPD [11, 12]. Furthermore, $\mathrm{AT}_{1}$ receptors are highly expressed within the lung [13] and modulate alveolar epithelial cell apoptosis [14] and lung fibroblast growth [15]. Thus there is the possibility that $\mathrm{AT}_{1}$ receptor blockers effect haematocrit and lung function in COPD. The effects of $\mathrm{AT}_{1}$ receptor blockade in patients with COPD have never been thoroughly investigated. Although cardiovascular comorbidity is common in patients with COPD and hence cardiovascular drugs are often used, there are only sparse data about the pulmonary and systemic effects of cardiovascular drugs in patients with COPD [16].

Thus several lines of evidence point to a potential benefit of $\mathrm{AT}_{1}$ receptor blockers in COPD. Therefore, a randomised controlled trial of $\mathrm{AT}_{1}$ receptor blockade was performed in order to

\section{AFFILIATIONS}

*Lungenfachklinik, Immenhausen, and Depts of ${ }^{*}$ Cardiology and Pneumology, and "Psychosomatics and Psychotherapy, section of Psychocardiology, Georg August University, Göttingen, and +Bereich Pneumologie, Evangelisches Krankenhaus Göttingen Weende e.v., Germany. ${ }^{\S}$ Dept of Medicine, University Hospital Aintree, Liverpool, UK.

CORRESPONDENCE

S. Andreas

Lungenfachklinik Immenhausen

Robert-Koch-Str. 3

34376 Immenhausen Germany

Fax: 495673501101

E-mail: sandreas@med.unigoettingen.de

Received:

August 222005

Accepted after revision: January 112006

\section{SUPPORT STATEMENT}

This investigator-initiated study was supported by an unrestricted grant from Sanofi-Synthelabo, Paris, France.

European Respiratory Journal Print ISSN 0903-1936 Online ISSN 1399-3003 
uncover possible clinical benefits and to provide pilot data for subsequent larger studies.

\section{METHODS}

\section{Study design}

The present study was a randomised placebo-controlled double-blind trial. Inclusion criteria were COPD patients on stable treatment (medication, supplemental oxygen and noninvasive ventilation) for $\geqslant 4$ weeks with a forced expiratory volume in one second (FEV1) of $<50 \%$ of the predicted value and an age of 30-80 yrs. Patients already treated with an ACE inhibitor or an $\mathrm{AT}_{1}$ receptor blocker were excluded, as were patients with any conventional indication for these drugs. Further exclusion criteria were known allergies to the study drug, chronic heart failure, untreated arterial hypertension, myocardial infarction within the last 6 months, dehydration, symptomatic hypotension, increased serum potassium levels and renal artery stenosis of $>70 \%$.

The study was approved by the local institutional ethics committee (Ethik-Kommission, Georg August Universität, Göttingen, Germany), and written informed consent was obtained from all patients before enrolment in the protocol.

\section{Study protocol}

Patients were recruited in cooperation with four local chest physicians. At the baseline visit, a physical examination, including measurement of cardiac frequency and blood pressure, together with measurements of spirometric data, respiratory muscle strength, arterial blood gas levels, ECG, Holter ECG for $20 \mathrm{~min}$ at rest, quadriceps muscle strength, echocardiography and exercise testing. Blood samples were collected for evaluation of haematology and liver and renal function, as well as measurement of levels of adrenalin, noradrenalin, aldosterone, renin, endothelin-1, atrial natriuretic peptide, interleukin-10 and leptin, as described previously [17]. In addition, the patients completed two health status questionnaires. Patients were then dispensed either $150 \mathrm{mg}$. day $^{-1}$ irbesartan or an identical placebo once daily, treatment being randomly assigned by sealed envelope. Blood pressure was measured before and $6 \mathrm{~h}$ after administration of the study drug. After 1 month, the dose of the study drug was increased to $300 \mathrm{mg} \cdot \mathrm{day}^{-1}$ under blood pressure control. After a further 3 months, the patients were re-examined and underwent the same tests as at the baseline examination. Individual compliance was evaluated by counting the number of tablets remaining on the second and third visits. Patients were interviewed by telephone about side-effects and changes in medication, supplemental oxygen and noninvasive ventilation at 2 and 3 months after the first visit.

\section{Lung function testing}

Spirometry was performed and lung volumes evaluated by body plethysmography (Master Lab; Jaeger, Hoechberg, Germany) [18]. The maximum static inspiratory pressure that a subject could generate at the mouth was measured at least five times at the residual volume, and the best trial recorded $[19,20]$.

\section{Cardiac frequency, exercise testing and ECG}

Mean cardiac frequency was derived from the 20-min Holter trace. A symptom-limited exercise test on a cycle ergometer was performed [21]. The load was increased by $15 \mathrm{~W} \cdot 3 \mathrm{~min}^{-1}$
(Variobike 550; Ergoline, Niederlauer, Germany). Transthoracic echocardiography was performed by a single experienced investigator (W. Körber) [22].

\section{Quality of life}

Quality of life was evaluated by two standardised questionnaires: the German version of the St George's Respiratory Questionnaire [23] and a questionnaire to evaluate the qualityof-life profile of chronically ill patients [24].

\section{Statistical analysis}

Based on the authors' previous as well as published data [10], the expected result was a difference of $0.4 \mathrm{kPa}$ in the primary end-point, maximum inspiratory pressure, with a power of $80 \%$ and a significance level of $<0.05$ in a two-tailed test with 30 patients in each group and a drop-out rate of $10 \%$. Randomisation success for baseline parameters was assessed using t-tests for independent samples, Mann-Whitney U-tests or Chi-squared tests, depending on type and distribution of data. Repeated-measures ANOVA with time as the withingroups factor and the time by treatment interaction was used to analyse the effects of treatment. If the requirements for performing the ANOVA were not met, nonparametric tests (Wilcoxon or McNemar) were employed instead. For the two pre-specified secondary end-points (total lung capacity and haematocrit), Bonferroni correction was used to adjust for multiple testing. Two-tailed tests were used and significance was accepted at a p-value of $<0.05$.

\section{RESULTS \\ Subjects}

Of the 225 patients screened for inclusion in the study, most were excluded since they were either already receiving an ACE inhibitor or suffered from chronic heart failure (fig. 1). Of the 60 patients included, 51 used inhalers containing $\beta_{2^{-}}$ sympathomimetic drugs. Inhaled anticholinergic agents or corticosteroids were used by 34 and 28 patients, respectively. Oral medications included corticosteroids taken by 28 patients and theophylline taken by 42 . Subject characteristics and baseline lung function test results were comparable between the two groups, although the treatment group was significantly shorter (table 1). Levels of creatinine, alanine aminotransferase, aspartate aminotransferase, bilirubin, fibrinogen, adrenalin and interleukin-10 were similar in both groups (data not shown).

Noninvasive ventilation was used by 10 patients, at least during their sleep. Long-term oxygen therapy was used by 20 patients for $\sim 15-18 \mathrm{~h} \cdot$ day $^{-1}$. Seventeen patients were current smokers. Sinus rhythm was found in 58 and atrial fibrillation in two. A right bundle branch block was diagnosed in 15 patients. Past medical history, physical examination, ECG recordings, laboratory investigations and pharmacological, as well as nonpharmacological, treatment revealed no significant difference between the groups at baseline (data not shown).

\section{Lung function tests}

After 4 months of treatment, irbesartan had not exerted a significant effect on the primary end-point, maximum inspiratory pressure (table 2). Irbesartan did not affect spirometric results, but total lung capacity fell (table 2). The p-value following Bonferroni correction for the secondary outcome 


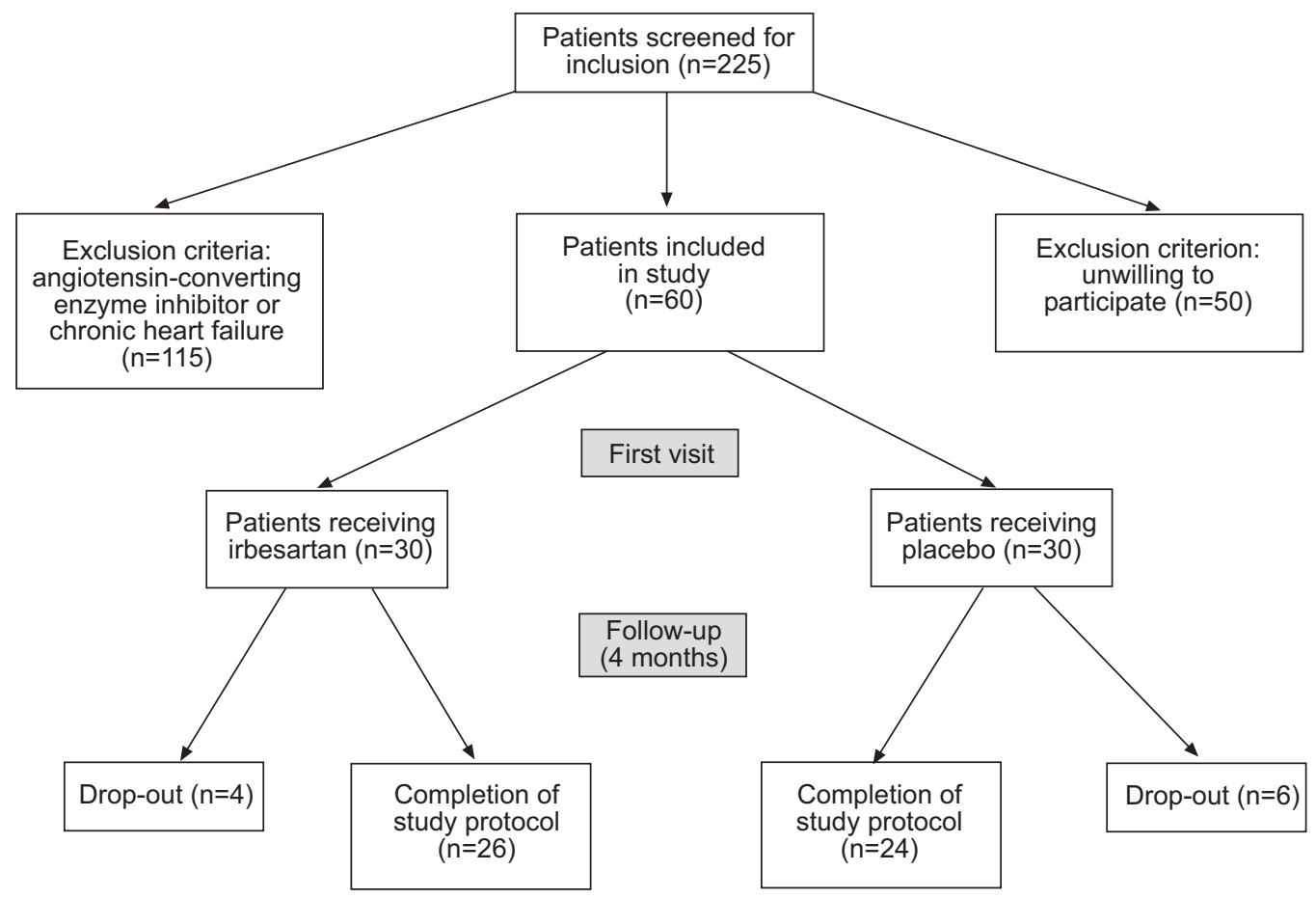

FIGURE 1. Screening, enrolment, allocation and follow-up of patients.

\section{TABLE 1 Subject characteristics and baseline conditions}

\begin{tabular}{|c|c|c|c|}
\hline & Placebo & Irbesartan & p-value \\
\hline Sex male/female & $23 / 7$ & $20 / 10$ & 0.39 \\
\hline Age yrs & $60.0 \pm 7.7$ & $62.8 \pm 8.5$ & 0.54 \\
\hline Height $\mathbf{c m}$ & $174 \pm 8.2$ & $169 \pm 6.5$ & 0.02 \\
\hline Weight kg & $74.4 \pm 15.3$ & $71.7 \pm 14.5$ & 0.43 \\
\hline Body mass index $\mathrm{kg} \cdot \mathrm{m}^{-2}$ & $24.5 \pm 3.7$ & $25.1 \pm 4.7$ & 0.59 \\
\hline FEV $1 /$ vital capacity $\%$ & $41.7 \pm 11.2$ & $42.7 \pm 10.3$ & 0.73 \\
\hline FEV $1 \%$ pred & $30.6 \pm 8.3$ & $32.9 \pm 9.1$ & 0.13 \\
\hline Vital capacity \% pred & $57.8 \pm 12.2$ & $63.4 \pm 13.1$ & 0.37 \\
\hline Raw,tot $\mathrm{KPa} \cdot \mathrm{L}^{-1} \cdot \mathrm{s}$ & $0.77 \pm 0.6$ & $0.65 \pm 0.4$ & 0.26 \\
\hline Left ventricular ejection fraction $\%$ & $64 \pm 10$ & $63 \pm 8$ & 0.72 \\
\hline Sodium mmol $\cdot \mathrm{L}^{-1}$ & $140.6 \pm 2.5$ & $140.1 \pm 3.0$ & 0.48 \\
\hline Potassium $\mathrm{mmol} \cdot \mathrm{L}^{-1}$ & $3.9 \pm 0.4$ & $4.2 \pm 0.5$ & 0.009 \\
\hline Noradrenalin $\mathbf{n g} \cdot \mathrm{L}^{-1}$ & $686 \pm 458$ & $624 \pm 419$ & 0.59 \\
\hline
\end{tabular}

Data are presented as mean $\pm \mathrm{SD}$. FEV 1 : forced expiratory volume in one second; \% pred: percentage of the predicted value; Raw,tot: total airway resistance.

variable, total lung capacity ( $\%$ pred), was 0.025 . There was a trend towards a lower residual volume/total lung capacity ratio $(\mathrm{p}=0.075$ (ANOVA for time by treatment interaction)) and a higher FEV1/vital capacity ratio $(p=0.072$ (ANOVA for time by treatment interaction)). Vital capacity, arterial oxygen and carbon dioxide tension and body weight remained unchanged.

\section{Blood pressure, exercise testing and ECG}

Following irbesartan, there was a significant decrease in systolic blood pressure measured in the morning (table 3), whereas no significant change was seen in the placebo group. However, the time by treatment interaction factor by ANOVA revealed no significance.

Irbesartan showed no significant effect on maximal workload and other parameters of the exercise test (table 3). ECG findings also remained unchanged. ECG revealed no significant changes in left ventricular end-diastolic and end-systolic diameters and thus no effect on ejection fraction (table 3). There was a reduction in right ventricular diameter in the placebo but not the irbesartan group.

Post hoc power calculations revealed that the study was underpowered for detecting modest changes in maximal oxygen uptake on exercise and quadriceps strength.

\section{Haematocrit and humoral effects}

Irbesartan led to a significant decrease in haemoglobin levels and haematocrit (fig. 2; table 4). The p-value following Bonferroni correction for the secondary outcome variable haematocrit was 0.0005 . Baseline haematocrits and the magnitude of the decrease following administration of irbesartan were nonsignificantly related $(r=0.34 ; p=0.09)$. In none of the patients treated with irbesartan did the haematocrit fall below $30 \%$.

Irbesartan did not effect adrenalin, noradrenalin, endothelin-1, atrial natriuretic peptide, ACE activity, interleukin-10 or leptin levels. Irbesartan led to a rise in plasma renin concentration from 38.0 (range 3-500) to $367.0(48-500) \mathrm{mU} \cdot \mathrm{mL}^{-1}(\mathrm{p}<0.001)$. Since placebo did not affect this parameter (baseline 39 (9500) $\mathrm{mU} \cdot \mathrm{mL}^{-1} ; 4$ months $\left.44.0(7-500) \mathrm{mU} \cdot \mathrm{mL}^{-1} ; \mathrm{p}=0.8\right)$, there was a significant difference in plasma renin concentration between the two groups at the end of the study $(\mathrm{p}<0.001)$. A decrease in aldosterone levels was observed in both the 
TABLE 2 Lung function test results

\begin{tabular}{|c|c|c|c|c|c|}
\hline & \multicolumn{2}{|c|}{ Placebo } & \multicolumn{2}{|c|}{ Irbesartan } & \multirow[t]{2}{*}{ p-value ${ }^{\#}$} \\
\hline & Baseline & 4 months & Baseline & 4 months & \\
\hline $\mathbf{P l}$, max $\mathrm{kPa}$ & $5.5 \pm 2.0$ & $5.8 \pm 2.2$ & $4.8 \pm 1.9$ & $4.5 \pm 2.0$ & 0.16 \\
\hline$P_{0.1, \max \mathrm{kPa}}$ & $3.3 \pm 1.0$ & $3.4 \pm 1.7$ & $2.9 \pm 1.0$ & $2.7 \pm 1.3$ & 0.47 \\
\hline FEV $1 /$ vital capacity $\%$ & $42 \pm 12$ & $38 \pm 11$ & $40 \pm 7$ & $43 \pm 13$ & 0.07 \\
\hline Raw,tot $\mathrm{kPa} \cdot \mathrm{L}^{-1} \cdot \mathrm{S}$ & $0.79 \pm 0.59$ & $0.64 \pm 0.4$ & $0.67 \pm 0.4$ & $0.69 \pm 0.5$ & 0.14 \\
\hline Total lung capacity $\%$ pred & $110.4 \pm 23$ & $121.7 \pm 25.8^{*}$ & $119.7 \pm 16$ & $113.7 \pm 19.2$ & 0.01 \\
\hline Residual volume/total lung capacity \% & $66.2 \pm 11.0$ & $70.4 \pm 10.3^{*}$ & $68.9 \pm 7.2$ & $68.8 \pm 7.3$ & 0.08 \\
\hline $\mathrm{Pa}, \mathrm{O}_{2} \mathrm{mmHg}$ & $64.4 \pm 10.4$ & $62.5 \pm 11.8$ & $65.7 \pm 10.4$ & $66.7 \pm 12$ & 0.31 \\
\hline $\mathrm{Pa}, \mathrm{CO}_{2} \mathrm{mmHg}$ & $43.3 \pm 3.4$ & $44.3 \pm 3.7$ & $42.9 \pm 3.6$ & $42.8 \pm 3.5$ & 0.45 \\
\hline Quadriceps maximal muscle strength N & $22.1 \pm 9.1$ & $22.3 \pm 9.8$ & $19.6 \pm 8.6$ & $21.6 \pm 9.3$ & 0.18 \\
\hline
\end{tabular}

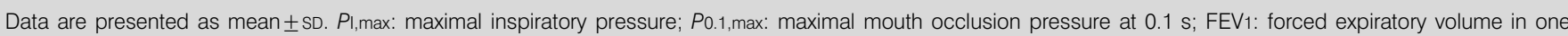
second; Raw,tot: total airway resistance; \% pred: percentage of the predicted value; $\mathrm{Pa}, \mathrm{O}_{2}$ : arterial oxygen tension; $\mathrm{Pa}, \mathrm{CO}_{2}$ : arterial carbon dioxide tension. For details of correction for multiple comparisons, see Statistical analysis. *: ANOVA for time by treatment interaction. *: $\mathrm{p}<0.05$ (ANOVA for time). $1 \mathrm{mmHg}=0.133 \mathrm{kPa}$.

TABLE 3 Cardiovascular parameters

\begin{tabular}{|c|c|c|c|c|c|}
\hline & \multicolumn{2}{|c|}{ Placebo } & \multicolumn{2}{|c|}{ Irbesartan } & \multirow[t]{2}{*}{ p-value ${ }^{\#}$} \\
\hline & Baseline & 4 months & Baseline & 4 months & \\
\hline Systolic blood pressure $\mathrm{mmHg}$ & $129.8 \pm 14.6$ & $129.1 \pm 15.5$ & $131.0 \pm 14.7$ & $124.4 \pm 16.1^{*}$ & 0.26 \\
\hline Diastolic blood pressure $\mathrm{mmHg}$ & 79. \pm 7.8 & $77.6 \pm 8.0$ & $78.7 \pm 9.2$ & $75.5 \pm 9.1$ & 0.45 \\
\hline Cardiac frequency beats $\cdot \mathrm{min}^{-1}$ & $88.8 \pm 13.1$ & $87.3 \pm 21.4$ & $82.5 \pm 10.6$ & $83.2 \pm 17.0$ & 0.68 \\
\hline RVEDD mm & $36.7 \pm 5.9$ & $33.6 \pm 4.7$ & $33.3 \pm 5.4$ & $33.1 \pm 5.6$ & 0.05 \\
\hline Maximal cardiac frequency beats $\cdot \mathrm{min}^{-1}$ & $124 \pm 15$ & $120 \pm 19$ & $128 \pm 15$ & $125 \pm 16$ & 0.62 \\
\hline Maximal V'E L. $\min ^{-1}$ & $28.3 \pm 8.9$ & $28.6 \pm 14.1$ & $29.2 \pm 12.2$ & $29.3 \pm 12.1$ & 0.89 \\
\hline$V^{\prime} E / V^{\prime} \mathrm{CO}_{2}$ slope & $25.6 \pm 10.4$ & $23.4 \pm 16.1$ & $25.1 \pm 11.7$ & $24.1 \pm 14.3$ & 0.81 \\
\hline Maximal respiratory quotient & $1.00 \pm 0.08$ & $1.00 \pm 0.07$ & $1.05 \pm 0.12$ & $0.96 \pm 0.15$ & 0.09 \\
\hline Maximal $\mathrm{V}^{\prime} \mathrm{O}_{2} \mathrm{~mL} \cdot \mathrm{min}^{-1}$ & $957 \pm 286$ & $885 \pm 433$ & $989 \pm 442$ & $986 \pm 411$ & 0.41 \\
\hline
\end{tabular}

Data are presented as mean \pm SD. LVEDD: left ventricular end-diastolic diameter; LVESD: left ventricular end-systolic diameter; RVEDD: right ventricular end-diastolic diameter; $V^{\prime} E$ : minute ventilation; $V^{\prime} \mathrm{CO}_{2}$ : carbon dioxide production; $\mathrm{V}^{\prime} \mathrm{O}_{2}$ : oxygen uptake. ${ }^{\#}$ : ANOVA for time by treatment interaction. ${ }^{*}: \mathrm{p}<0.05$ (ANOVA for time) $1 \mathrm{mmHg}=0.133 \mathrm{kPa}$

irbesartan group (from 11.0 (range 0.75-120.0) to $5.0(0.75-$ 113.0) $\left.\mathrm{ng} \cdot \mathrm{dL}^{-1} ; \mathrm{p}<0.05\right)$ and the placebo group (from $8.5(0.75$ $120.0)$ to $\left.3.1(0.75-25.0) \mathrm{ng} \cdot \mathrm{dL}^{-1} ; \mathrm{p}<0.05\right)$. Potassium levels differed between the two groups at the beginning of the study and showed no significant change over the 4-month period. Serum sodium concentrations increased in patients receiving placebo, whereas they remained constant in patients receiving irbesartan (table 4).

\section{Safety, side-effects and quality of life}

Treatment with bronchodilatators, corticosteroids, supplemental oxygen or noninvasive ventilation was not significantly impacted upon by study medication. Irbesartan had no significant effect on creatinine, bilirubin or fibrinogen levels.
A significant rise in alanine aminotransferase levels was found (table 4), whereas aspartate aminotransferase levels showed no significant difference (ANOVA for time by treatment interaction).

Evaluation of the questionnaires revealed no difference between the two groups concerning side-effects. At the first follow-up appointment, a total of 19 patients complained about side-effects, whereas, at the second follow-up appointment, only six patients reported such effects.

Quality of life, as measured by the questionnaires, was low in both groups (table 5). Using the St George's Respiratory Questionnaire, the placebo group scored significantly higher (i.e. worse) than the irbesartan group regarding both total score 


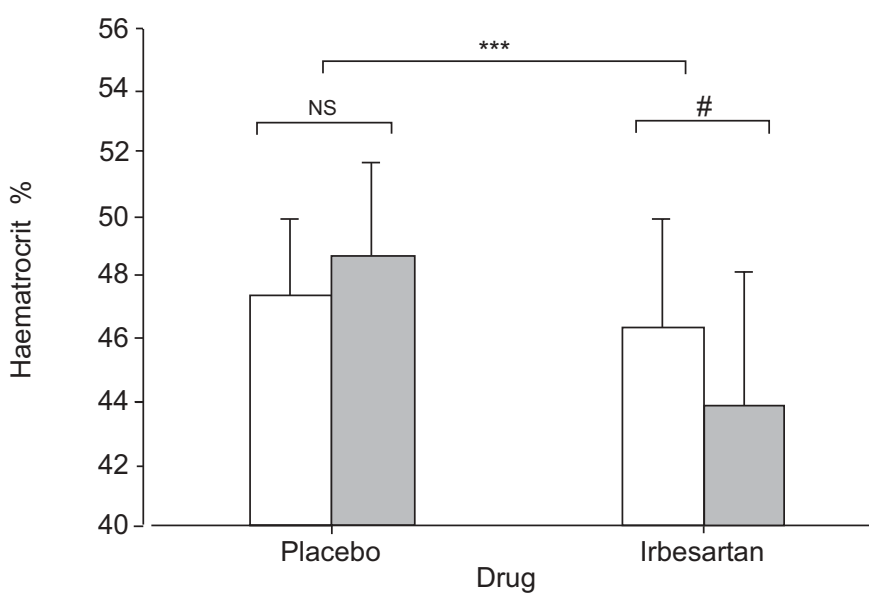

FIGURE 2. Effects of placebo and irbesartan on haematocrit at baseline ( $\square$ ) and at follow-up at 4 months ( $\square$ ). NS: nonsignificant. ${ }^{*}: p=0.003$; ${ }^{* * *}: p<0.001$

\begin{tabular}{|c|c|c|c|c|c|}
\hline \multirow[t]{3}{*}{ TABLE 4} & \multicolumn{5}{|c|}{ Blood tests } \\
\hline & \multicolumn{2}{|c|}{ Placebo } & \multicolumn{2}{|c|}{ Irbesartan } & \multirow[t]{2}{*}{ p-value } \\
\hline & Baseline & 4 months & Baseline & 4 months & \\
\hline $\begin{array}{l}\text { Haematocrit } \\
\%\end{array}$ & $47.5 \pm 2.4$ & $48.7 \pm 3.0$ & $46.4 \pm 3.6$ & $43.9 \pm 4.3^{\star *}$ & 0.0001 \\
\hline $\mathrm{Hb} \mathbf{g} \cdot \mathrm{dL}^{-1}$ & $15.7 \pm 0.9$ & $15.9 \pm 1.1$ & $15.1 \pm 1.3$ & $14.2 \pm 1.6^{* *}$ & 0.002 \\
\hline Sodium mM & $140.1 \pm 2.5$ & $142.1 \pm 3.2^{*}$ & $140.2 \pm 3.0$ & $140.2 \pm 3.0$ & 0.021 \\
\hline ALT U. $L^{-1}$ & $24.2 \pm 14.4$ & $22.3 \pm 13.4$ & $18.1 \pm 10.2$ & $22.0 \pm 9.9^{*}$ & 0.047 \\
\hline
\end{tabular}

Data are presented as mean $\pm \mathrm{SD}$. Hb: haemoglobin; ALT: alanine aminotransferase. For details of correction for multiple comparisons, see Statistical analysis. ${ }^{*}$ : ANOVA for time by treatment interaction. *: $p<0.05 ;{ }^{*}: p<0.001$ (ANOVA for time)

and subscale scores "symptoms" and "activity" at baseline (all $\mathrm{p}<0.01$ ). However, neither group changed significantly during the course of the study.

\section{DISCUSSION}

Although commonly used, there is only sparse evidence of any pulmonary and/or systemic effects of cardiovascular drugs in patients with COPD [16]. ACE inhibitors often induce cough, and acute bronchospasm is a rare but serious adverse reaction [16]. For $\beta$-blockers, there is some evidence of increased airway resistance in COPD patients [16]. Diuretics have not been investigated in patients with COPD but have theoretical risks such as alkalosis [16].

In the present study, it was hypothesised that the properties of one class of cardiovascular drug, the $\mathrm{AT}_{1}$ receptor blocker, would be valuable in COPD patients. It was found that the primary end-point, maximum inspiratory pressure, was not affected by irbesartan, the $\mathrm{AT}_{1}$ receptor blocker used, despite evidence that it was biologically active at the doses given. However, irbesartan did reduce the haematocrit and was well tolerated.

\section{Skeletal muscle function and inspiratory pressure}

The present study rationale came from observations that, in COPD, the sympathetic nervous system and the reninangiotensin system (RAS) are activated [5-7, 25], with a welldescribed interaction between the two systems [26, 27]. Sympathetic nervous system activation is associated with impaired endothelial function and decreased exercise-induced vasodilatation in skeletal muscle, a decrease in the number of type-1 (slow/endurance) muscle fibres, cardiomyocyte injury and apoptosis, and catabolic/anabolic imbalance, with muscle wasting and lipolysis [28, 29].

Genetic studies suggest that, in healthy subjects, increased ACE activity and high angiotensin II plasma levels mediate greater strength gains, perhaps via muscle hypertrophy, whereas lower angiotensin II levels mediate enhanced endurance performance, perhaps via changes in substrate availability, muscle fibre type and efficiency (for review, see [27]). A reduction in ACE activity reverses the decline in peripheral muscle performance in patients with congestive heart failure [27]. In a rat model of right heart failure, the $\mathrm{AT}_{1}$ receptor blocker irbesartan prevented the development of apoptosisdependent muscle atrophy [9]. Moreover, in patients with left heart failure, maximum inspiratory pressure was improved by ACE inhibition in an uncontrolled study [10].

Thus it seemed reasonable to suggest that $\mathrm{AT}_{1}$ receptor blockers might affect the endurance performance of skeletal and respiratory muscle function in COPD patients. In the present study, it was not possible to demonstrate any

\section{TABLE 5 Quality of life}

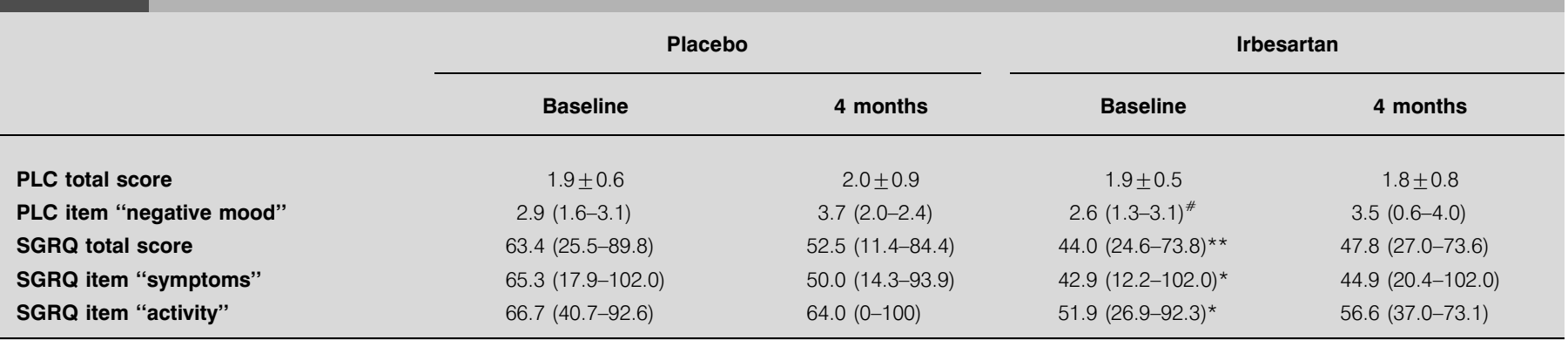

Data are presented as mean \pm SD or median (range). PLC: Quality of Life Profile for the Chronically III; SGRQ: St George's Respiratory Questionnaire. *: $\mathrm{p}<0.05$; **: $p<0.001$ versus irbesartan at baseline (ANOVA for time); ${ }^{*}: p<0.05$ (Wilcoxon for time). 
improvement in maximal inspiratory pressure or maximal quadriceps muscle strength. Other methods that better reflect endurance performance of the diaphragm or the quadriceps might have been more appropriate for detecting the hypothetical effects of the study drug. However, the present data suggest that more specific measures for identifying patients with the greatest activation of the sympathetic and RAS are needed before this intervention can be rigorously tested, as an effect was not seen in a reasonable number of COPD patients who might reasonably be thought to exhibit this activation.

\section{Haematocrit}

Plasma renin activity and aldosterone concentration are elevated in patients with COPD [7, 25]. The activation of the RAS is particularly pronounced in patients with secondary erythrocytosis [12], and angiotensin II enhances erythropoietin-stimulated erythroid proliferation in vitro [11] Accordingly, losartan, an $\mathrm{AT}_{1}$ receptor blocker, reduced the haematocrit in patients with hypoxaemic COPD and secondary erythrocytosis in a previous uncontrolled study [30]. These findings are now extended as a similar effect of irbesartan is reported in the present controlled trial in patients with COPD without frank erythrocytosis. There was a trend towards a larger fall in hematocrit in the patients with high baseline haematocrit. Interestingly, $\mathrm{AT}_{1}$ receptor blockade did not affect haematocrit in patients with chronic heart failure, who also show an activated RAS but in whom hypoxaemia, by day or intermittently at night, is not an important clinical problem.

Anaemia is present in some COPD patients with cachexia and might be aggravated by $\mathrm{AT}_{1}$ receptor blockade. This might impair oxygen delivery, cause cardiac output to increase and thus impair right heart function, and ultimately cause right heart failure. However, anaemia with a haematocrit of $<30 \%$ was not noticed in the present study. Conversely, erythrocytosis is related to cardiovascular disease, especially myocardial infarction, independent of other risk factors such as smoking $[31,32]$. Thus, it is conceivable, albeit speculative, that adjunctive $\mathrm{AT}_{1}$ receptor blockade in a small-but-well-defined subgroup of COPD patients reduces cardiovascular morbidity by reducing erythrocytosis. In any case, before performing phlebotomy in patients with COPD, an $\mathrm{AT}_{1}$ receptor blocker can be tried.

\section{Lung function}

In the present study, there was no significant effect on spirometric results. However, irbesartan led to a decrease in total lung capacity, whereas there was a trend towards an increase in the placebo group. This finding is difficult to explain and should not be overemphasised, since it was not the primary end-point, and the significance found in the time by treatment interaction was due partly to the changes observed in the placebo group.

In patients with bronchial asthma, $\mathrm{AT}_{1}$ receptor blockade slightly reduced bronchial hyperresponsiveness to methacholine [33]. In the current COPD patients, no effect on FEV1 or airway resistance was noticed.

Since there was a trend towards a reduction in residual volume/total lung capacity ratio, and since FEV1, arterial oxygen tension and exercise capacity were not impaired, it is also unlikely that the reduction in total lung capacity was due to restrictive lung disease, e.g. by pulmonary fluid accumulation.

Indeed, recent genetic data presented by HOPKINSON et al. [34] are consistent with an effect of $\mathrm{AT}_{1}$ receptor blockade on lung function. In COPD patients with the DD genotype, i.e. homozygous for deletion of the ACE gene (which causes markedly increased angiotensin II activity at the receptor level), functional residual capacity was significantly higher [34].

\section{Blood pressure, cardiac frequency and side-effects}

There was a drop in systolic blood pressure of $\sim 6 \mathrm{mmHg}$ following irbesartan that was insignificant compared to placebo. This minor effect on blood pressure is comparable to previous studies in patients with an activated RAS due to heart failure and normal blood pressure [35].

The increase in plasma renin activity following irbesartan in the present patients was expected and provided an indirect measure of compliance with treatment. In healthy subjects and patients with arterial hypertension, renin and angiotensin II levels increased, whereas aldosterone levels did not change significantly, following irbesartan administration [36, 37]. In the present patients, a reduction in serum sodium concentration was noticed that can be explained by the promotion of urinary sodium excretion by $\mathrm{AT}_{1}$ receptor blockade [38] in the presence of impaired sodium excretion in patients with severe COPD [39].

As in former large studies on patients with renal disease, the study drug was well tolerated [40]. In the present patients, the incidence of side-effects was similar to that with placebo. However, alanine aminotransferase activity increased slightly, an effect that has not been seen in the previous large studies on $\mathrm{AT}_{1}$ receptor blockade.

\section{Limitations}

Randomisation yielded an irbesarten group with significantly lower baseline serum potassium levels and lower height, as well as a trend towards lower maximal inspiratory pressures. However, the statistical method used (ANOVA with time by treatment interaction) takes differences in baseline characteristics into account. The small sample size and inhomogeneous cohort (with regard to age, sex, size, pharmacotherapy and respiratory support) does not permit the firm exclusion of a significant effect of $\mathrm{AT}_{1}$ receptor blockade on respiratory muscle strength or exact power calculations. Age, especially, has a profound impact on muscle function and disease progression.

\section{Conclusions}

In conclusion, angiotensin II receptor blockade did not improve respiratory muscle strength or exercise capacity, but was otherwise well tolerated in patients with stage III and IV chronic obstructive pulmonary disease. The reduction in haematocrit following irbesartan might be disadvantageous or beneficial depending on baseline haematocrit. This and the impact on total lung capacity, also hinted at in previous genetic data, deserve prospective investigation. The present data indicate that cardiovascular drugs commonly used to treat comorbid conditions in chronic obstructive pulmonary disease 
patients can have subtle and unanticipated effects. Developing appropriate methodologies to test these interactions is an important challenge for future research.

\section{REFERENCES}

1 Calverley PM, Walker P. Chronic obstructive pulmonary disease. Lancet 2003; 362: 1053-1061.

2 Croxton TL, Weinmann GG, Senior RM, Wise RA, Crapo JD, Buist AS. Clinical research in chronic obstructive pulmonary disease: needs and opportunities. Am J Respir Crit Care Med 2003; 167: 1142-1149.

3 Reid MB. COPD as a muscle disease. Am J Respir Crit Care Med 2001; 164: 1101-1102.

4 Celli BR, MacNee W. Standards for the diagnosis and treatment of patients with COPD: a summary of the ATS/ ERS position paper. Eur Respir J 2004; 23: 932-946.

5 Andreas S, Anker SD, Scanlon PD, Somers VK. Neurohumoral activation as a link to systemic manifestation of chronic lung disease. Chest 2005; 128: 3618-3624.

6 Heindl S, Lehnert M, Criée CP, Hasenfuß G, Andreas S. Marked sympathetic activation in patients with chronic respiratory failure. Am J Respir Crit Care Med 2001; 164: 597-601.

7 Stewart AG, Waterhouse JC, Billings CG, Baylis P, Howard P. Effects of angiotensin converting enzyme inhibition on sodium excretion in patients with hypoxaemic chronic obstructive pulmonary disease. Thorax 1994; 49: 995-998.

8 Esler M. Differentiation in the effects of the angiotensin II receptor blocker class on autonomic function. J Hypertens 2002; 20: Suppl. 5, S13-S19.

9 Dalla Libera L, Ravara B, Angelini A, et al. Beneficial effects on skeletal muscle of the angiotensin II type 1 receptor blocker irbesartan in experimental heart failure. Circulation 2001; 103: 2195-2200.

10 Coirault C, Hagege A, Chemla D, Fratacci MD, Guerot C, Lecarpentier Y. Angiotensin-converting enzyme inhibitor therapy improves respiratory muscle strength in patients with heart failure. Chest 2001; 119: 1755-1760.

11 Mrug M, Stopka T, Julian BA, Prchal JF, Prchal JT. Angiotensin II stimulates proliferation of normal early erythroid progenitors. J Clin Invest 1997; 100: 2310-2314.

12 Vlahakos DV, Kosmas EN, Dimopoulou I, et al. Association between activation of the renin-angiotensin system and secondary erythrocytosis in patients with chronic obstructive pulmonary disease. Am J Med 1999; 106: 158-164.

13 Llorens-Cortes C, Greenberg B, Huang H, Corvol P. Tissular expression and regulation of type 1 angiotensin II receptor subtypes by quantitative reverse transcriptasepolymerase chain reaction analysis. Hypertension 1994; 24 : 538-548.

14 Wang R, Zagariya A, Ibarra-Sunga O, et al. Angiotensin II induces apoptosis in human and rat alveolar epithelial cells. Am J Physiol 1999; 276: L885-L889.

15 Molteni A, Ward WF, Ts'ao CH, et al. Cytostatic properties of some angiotensin I converting enzyme inhibitors and of angiotensin II type I receptor antagonists. Curr Pharm Des 2003; 9: 751-761.

16 Dart RA, Gollub S, Lazar J, Nair C, Schroeder D, Woolf SH. Treatment of systemic hypertension in patients with pulmonary disease: COPD and asthma. Chest 2003; 123: 222-243.

17 Andreas S, Reiter H, Lüthje L, et al. Differential effects of theophylline on sympathetic excitation, hemodynamics and breathing in congestive heart failure. Circulation 2004; 110: 2157-2162.

18 Quanjer PH, Tammeling GJ, Cotes JE, Pedersen OF, Peslin R, Yernault JC. Lung volumes and forced ventilatory flows. Eur Respir J 1993; 6: Suppl. 16, 5-40.

19 American Thoracic Society, European Respiratory Society. ATS/ERS Statement on Respiratory Muscle Testing. Am J Respir Crit Care Med 2002; 166: 518-624.

20 Windisch W, Hennings E, Sorichter S, Hamm H, Criee CP. Peak or plateau maximal inspiratory mouth pressure: which is best? Eur Respir J 2004; 23: 708-713.

21 Gibbons RJ, Balady GJ, Beasley JW, et al. ACC/AHA Guidelines for Exercise Testing. J Am Coll Cardiol 1997; 30: 260-311.

22 Quinones MA, Douglas PS, Foster E, et al. American College of Cardiology/American Heart Association clinical competence statement on echocardiography: a report of the American College of Cardiology/American Heart Association/American College of Physicians-American Society of Internal Medicine Task Force on Clinical Competence. Circulation 2003; 107: 1068-1089.

23 Jones PW, Quirk FH, Baveystock CM, Littlejohns P. A selfcomplete measure of health status for chronic airflow limitation. The St. George's Respiratory Questionnaire. Am Rev Respir Dis 1992; 145: 1321-1327.

24 Goldbeck L, Schmitz TG. Comparison of three generic questionnaires measuring quality of life in adolescents and adults with cystic fibrosis: the 36-item short form health survey, the quality of life profile for chronic diseases, and the questions on life satisfaction. Qual Life Res 2001; 10: 23-36.

25 Kiely DG, Cargill RI, Wheeldon NM, Coutie WJ, Lipworth BJ. Haemodynamic and endocrine effects of type 1 angiotensin II receptor blockade in patients with hypoxaemic cor pulmonale. Cardiovasc Res 1997; 33: 201-208.

26 Reid IA. Interactions between ANG II, sympathetic nervous system, and baroreceptor reflexes in regulation of blood pressure. Am J Physiol 1992; 262: E763-E778.

27 Jones A, Woods DR. Skeletal muscle RAS and exercise performance. Int J Biochem Cell Biol 2003; 35: 855-866.

28 Anker SD, Coats AJ. Cardiac cachexia: a syndrome with impaired survival and immune and neuroendocrine activation. Chest 1999; 115: 836-847.

29 Packer $M$. The neurohormonal hypothesis: a theory to explain the mechanism of disease progression in heart failure. J Am Coll Cardiol 1992; 20: 248-254.

30 Vlahakos DV, Marathias KP, Kosmas EN. Losartan reduces hematocrit in patients with chronic obstructive pulmonary disease and secondary erythrocytosis. Ann Intern Med 2001; 134: 426-427.

31 Sorlie PD, Garcia-Palmieri MR, Costas R Jr, Havlik RJ. Hematocrit and risk of coronary heart disease: the Puerto Rico Health Program. Am Heart J 1981; 101: 456-461.

32 Burge PS, Johnson WS, Prankerd TA. Morbidity and mortality in pseudopolycythaemia. Lancet 1975; 1: 1266-1269.

33 Tanaka H, Teramoto S, Oashi K, et al. Effects of candesartan on cough and bronchial hyperresponsiveness 
in mildly to moderately hypertensive patients with symptomatic asthma. Circulation 2001; 104: 281-285.

34 Hopkinson NS, Nickol AH, Payne J, et al. Angiotensin converting enzyme genotype and strength in chronic obstructive pulmonary disease. Am J Respir Crit Care Med 2004; 170: 395-399.

35 Havranek EP, Thomas I, Smith WB, et al. Dose-related beneficial long-term hemodynamic and clinical efficacy of irbesartan in heart failure. J Am Coll Cardiol 1999; 33: 1174-1181.

36 van den Meiracker AH, Admiraal PJ, Janssen JA, et al. Hemodynamic and biochemical effects of the $\mathrm{AT}_{1}$ receptor antagonist irbesartan in hypertension. Hypertension 1995; 25: 22-29.
37 Schmitt F, Martinez F, Brillet G, et al. Acute renal effects of $\mathrm{AT}_{1}$-receptor blockade after exogenous angiotensin II infusion in healthy subjects. J Cardiovasc Pharmacol 1998; 31: 314-321.

38 Burnier M. Angiotensin II type 1 receptor blockers. Circulation 2001; 103: 904-912.

39 Stewart AG, Bardsley PA, Baudouin SV, et al. Changes in atrial natriuretic peptide concentrations during intravenous saline infusion in hypoxic cor pulmonale. Thorax 1991; 46: 829-834.

40 Parving $\mathrm{HH}$, Lehnert H, Brochner-Mortensen J, Gomis R, Andersen S, Arner P. The effect of irbesartan on the development of diabetic nephropathy in patients with type 2 diabetes. N Engl J Med 2001; 345: 870-878. 